\title{
Pemanfaatan Media Sosial dan E-Commerce Sebagai Upaya Pemasaran Bakmi Jawa di Desa Piyaman
}

\author{
Agata Bening Arinta ${ }^{1}$, Inboki Insoraki Ayu Marjen ${ }^{1}$, Cindy Angela Nayoan ${ }^{1}$, Fortuna Alya Azhari ${ }^{1}$, Tesya Lonika Samson ${ }^{1}$, Yustina \\ Violieta Prabawati ${ }^{1}$, Evangelisca Trisna Herlin Adinda ${ }^{1}$, I Gede Ari Chandra Wiguna ${ }^{1}$, Mercy Grace Olivia Manurung ${ }^{1}$, Alvin Christa \\ Yudiasmara $^{1}$, Sendy Junedi ${ }^{1}$ \\ Universitas Atma Jaya Yogyakarta, Jl. Babarsari No.44, Janti, Caturtunggal, Kec. Depok, Kabupaten Sleman, \\ Daerah Istimewa Yogyakarta 55281 \\ Email: sendy.junedi@uajy.ac.id
}

\begin{abstract}
The Covid-19 pandemic have an economic impact on increasing unemployment and change in product marketing methods from offline to online. Based on the secondary data, it is known that most of the residents in Piyaman Village, Wonosari District, Gunungkidul Regency are entrepreneur of Bakmi Jawa . However, the percentage of unemployment in Piyaman Village is quite high. To increase the sales of Bakmi Jawa and create jobs for the unemployed residents, it is necessary to develop the potency of Bakmi Jawa in Piyaman Village. The promotion and marketing method of Bakmi Jawa needs to be done digitally using the social media Instagram and Tokopedia which are the most developed media in Indonesia. This program was carried out by introducing the usage of Instagram and Tokopedia for promotion and digital marketing (e-commerce) of Bakmi Jawa to a wider range of consumers. In addition, the diversification of frozen noodle was also introduced to answer the marketing needs of Bakmi Jawa to consumers in various regions. The progran method was performed qualitatively by analyzing secondary data. The program was carried out by preparing e-book and video about e-commerce methods and diversification of frozen noodles.
\end{abstract}

Keywords - Piyaman Village, Bakmi Jawa, Social Media, Ecommerce, Frozen Bakmi

\begin{abstract}
Abstrak - Adanya pandemi Covid-19 memberikan dampak ekonomi meningkatnya pengangguran dan perubahan metode pemasaran produk dari offline menjadi online. Berdasarkan data sekunder yang dikumpulkan diketahui bahwa sebagian besar penduduk Desa Piyaman, Kecamatan Wonosari, Kabupaten Gunungkidul merupakan pedagang bakmi Jawa. Meskipun demikian persentase pengangguran di Desa Piyaman cukup tinggi. Maka dari itu untuk meningkatkan penjualan bakmi Jawa dan membuka lapangan pekerjaan bagi penduduk perlu dilakukan pengembangan potensi bakmi Jawa Desa Piyaman. Metode promosi dan pemasaran bakmi Jawa perlu dilakukan secara digital menggunakan media sosial Instagram dan Tokopedia yang merupakan media paling berkembang di Indonesia. Program pengabdian ini dilakukan dengan memperkenalkan penggunaan Instagram dan Tokopedia untuk promosi dan pemasaran digital (ecommerce) bakmi Jawa kepada konsumen yang lebih luas. Selain itu, diperkenalkan juga diversifikasi bakmi frozen untuk menjawab kebutuhan pemasaran bakmi Jawa kepada konsumen di berbagai daerah. Metode pengabdian dilakukan secara kualitatif dengan menganalisa data sekunder. Program dilaksanakan dalam bentuk pembuatan e-book dan video mengenai metode e-commerce dan diversifikasi bakmi frozen.
\end{abstract}

Kata Kunci-Desa Piyaman, Bakmi Jawa, Media Sosial, Ecommerce, Bakmi Frozen

\section{PENDAHULUAN}

Desa Piyaman merupakan salah satu desa yang berada di Kecamatan Wonosari, Kabupaten Gunungkidul, Provinsi Daerah Istimewa Yogyakarta. Lokasi desa ini berada pada jarak sekitar 4 kilometer dari Kabupaten Gunungkidul dan sekitar 43 kilometer dari kota Yogyakarta. Desa ini memiliki luas sebesar 649 hektar, sekitar 9,08 persen dari luas wilayah Kecamatan Wonosari. Desa Piyaman terbagi dalam 11 dusun antara lain ; Dusun Ngerboh I,Dusun Ngerboh II, Dusun Kemorosari I, Dusun Kemorosari II, Dusun Piyaman I, Dusun Piyaman II, Dusun Pakeljaluk, Dusun Ngemplak, Dusun Pakelrejo, Dusun Budegan I, dan Dusun Budegan II. Populasi kependudukan terbesar berada di Dusun Kemorosari II dengan jumlah jiwa 1671 jiwa.

Data kependudukan berdasarkan pendidikan terbanyak adalah SLTA/sederajat dengan jumlah 2089 jiwa dan presentase $23,60 \%$. Data kependudukan berdasarkan pekerjaan terbesar adalah belum atau tidak bekerja dengan jumlah 1647 jiwa serta presentase 18,60\% dan wiraswasta sebanyak 1417 jiwa dengan persentase $16 \%$ [1].

Salah satu potensi desa yang dikenal di Desa Piyaman adalah produksi bakminya. Desa Piyaman terkenal sebagai tempat asal para pedagang bakmi Jawa [2]. Bakmi Jawa sendiri dahulu dikenal dengan sebutan bakmi rebus atau bakmi godhog dalam bahasa jawa. Keistimewaan dari bakmi Jawa ini adalah dimasak secara tradisional, menggunakan tungku tanah liat atau anglo, serta api dari arang [3]. Usaha bakmi di Desa Piyaman diwariskan secara turun temurun dari orang tua ke anak-anaknya. Sebagian para pedagang bakmi ini telah berjualan di luar Jawa dan memperkenalkan bakmi Jawa serta resep kepada penduduk setempat [4].

Pedagang bakmi Jawa menjajakan dagangannya secara langsung dengan menggunakan gerobak tempat memasak bakmi di depan tempat mereka berjualan [3]. Mengingat masa pandemi Covid-19 dan pemberlakuan PSBB (Pembatasan Sosial Berskala Besar), cara berdagang demikian sulit dilakukan dan bahkan menyebabkan terjadinya penurunan aktivitas jual beli [5]. Melalui program pengabdian masyarakat ini, diajukan upaya mengatasi penurunan penjualan bakmi Jawa di Desa Piyaman melalui pengenalan metode pemasaran yang tepat dan modifikasi produk untuk menyesuaikan proses pemasaran yang baru.

Metode pemasaran yang dapat dilakukan oleh pedagang bakmi Jawa di Desa Piyaman adalah digital marketing. Digital marketing atau yang lebih dikenal dengan pemasaran 
digital adalah suatu strategi pemasaran yang memanfaatkan teknologi dan media digital. Teknologi dan media digital ini menghubungkan penjual dengan konsumen dengan lebih cepat, efektif, dan efisien. Pemanfaatan teknologi dan media digital ini diharapkan dapat membantu pemasaran bakmi Jawa Desa Piyaman lebih terstruktur, terencana, dan tepat sasaran. Sehingga diharapkan memberikan pelayanan yang dibutuhkan konsumen, membangun relasi yang baik dengan konsumen, meningkatkan loyalitas konsumen, dan memperoleh keuntungan [6].

Pemasaran digital memiliki keuntungan lain, yaitu dapat menjangkau banyak konsumen dari berbagai tempat. Ada 6 saluran utama yang digunakan dalam media digital, yakni search engine marketing, online pr, online partnerships, interactive advertising, opt-in email marketing, dan social media marketing [7].

Saluran pemasaran digital yang dapat dimanfaatkan oleh masyarakat Desa Piyaman adalah social media marketing menggunakan media sosial, seperti Facebook, Instagram, $e$ Commerce, dan lain-lain. Pemasaran melalui media sosial ini memanfaatkan fitur-fitur yang ada di media sosial tersebut untuk menciptakan interaksi dua arah antara penjual dan konsumen [7]. Dalam hal ini pemasaran bakmi Jawa di Desa Piyaman akan dilakukan dengan menggunakan media sosial Instagram dan e-commerce Tokopedia.

Mengingat Instagram merupakan media sosial yang fokus pada aktivitas berbagi foto dan video, sehingga memungkinkan pedagang untuk mempromosikan produkproduk secara langsung [8]. Selain itu, Instagram juga memiliki fitur hashtag (\#) yang memudahkan pengguna atau konsumen untuk mencari bakmi Jawa [9].

E-commerce Tokopedia diketahui berada pada peringkat pertama sebagai $e$-commerce yang paling banyak dikunjungi oleh masyarakat Indonesia pada periode Januari 2021. Jumlah kunjungan per bulan ini sebanyak 129,1 juta kunjungan, sehingga dengan memanfaatkan Tokopedia akan memperluas pemasaran bakmi Jawa [10].

Selain metode promosi dan pemasaran, program pengabdian masyarakat ini juga menyampaikan diversifikasi bakmi Jawa dalam bentuk frozen agar dapat dipasarkan jarak jauh mengikuti kebutuhan pemasaran digital. Dengan metode promosi dan pemasaran digital serta diversifikasi produk diharapkan dapat meningkatkan pendapatan pedagang bakmi Jawa saat pandemi dan membuka lapangan pekerjaan untuk menurunkan pengangguran di Desa Piyaman.

\section{MEtode PENGABDiAN}

\section{A. Jenis Penelitian}

Pelaksanaan program pengabdian masyararakt ini merupakan program Kuliah Kerja Nyata (KKN) Universitas Atma Jaya Yogyakarta (UAJY). Program KKN ini dilaksanakan dengan format KKN Society 5.0 yang berlangsung secara daring karena dalam masa pandemi Covid-19. Program yang dilaksanakan merupakan penelitian kualitatif dengan cara menyelidiki, menemukan, menggambarkan, dan menjelaskan kualitas atau keistimewaan dari pengaruh sosial yang tidak dapat dijelaskan, diukur atau digambarkan melalui pendekatan kuantitatif [11]. Melalui metode ini proses peristiwa yang terjadi dapat dilihat berdasarkan alur yang runtut serta akan diperoleh informasi yang lebih banyak dan lengkap [12].

B. Tahapan Pelaksanaan Program

\section{Pencarian Data Sekunder}

Data yang digunakan kelompok dalam pelaksanaan KKN ini adalah data sekunder. Data sekunder adalah data dari peneliti-peneliti lain yang diperoleh dari media-media lain, seperti media cetak, media massa, dan media online [13]. Pada pelaksanaan KKN ini kelompok menggunakan data sekunder dari website resmi Desa Piyaman, artikel dari media online mengenai Desa Piyaman, dan media sosial.

Penulis tidak dapat mengumpulkan data primer secara langsung karena berkaitan dengan pandemi Covid-19 yang masih terdapat di Indonesia khususnya Kabupaten Gunungkidul, Provinsi Daerah Istimewa Yogyakarta. Meskipun demikian data sekunder dapat digunakan sebagai dasar pijakan dalam mengidentifikasi potensi dan permasalahan desa, serta menetapkan strategi untuk pengembangan potensi dan penyelesaian permasalahan desa.

\section{Pemilihan Potensi Desa yang Akan Dikembangkan}

Melalui pencarian data sekunder mengenai potensi desa yang dimiliki oleh Desa Piyaman, penulis menemukan beberapa potensi desa yang kemudian dipilih dengan mempertimbangkan data sekunder perkejaan penduduk desa.

3. Pemilihan Ide Untuk Mengembangakan Potensi Tersebut

Ide pengembangan potensi bakmi Jawa dipilih dengan melihat perbedaan situasi penjualan sebelum dan saat pandemi Covid-19.

\section{Pelaksanaan Program}

Program ini dilaksanakan dengan pembuatan video dan ebook yang bisa terakses oleh masyarakat desa via online. Isi dari e-book dan video akan mirip dengan durasi waktu untuk video adalah 7-15 menit dan kapasitas $1 \mathrm{~GB}$.

\section{Pelaporan}

Dilakukan secara internal untuk Lembaga Penelitian dan Pengabdian Masyarakat (LPPM) dan eksternal untuk masyarakat serta akademisi melalui jurnal.

\section{HASIL DAN PEMBAHASAN}

Desa Piyaman memiliki luas sebesar 857.2570,68 Ha serta terletak di $7.9400^{\circ}$ pada garis lintang dan $110.5958^{\circ}$ pada garis bujur dengan ketinggian 359 meter di atas permukaan laut. Jumlah penduduk Desa Piyaman adalah sebanyak 8854 jiwa yang terdiri dari 4463 perempuan dan 4391 laki-laki [1]. Batas-batas wilayah Desa Piyaman adalah sebagai berikut:

- Barat: Desa Logandeng, Kecamatan Playen

- Timur :Desa Bejiharjo, Kecamatan Karangmojo

- Utara : Desa Gari, Kecamatan Wonosari

- Selatan : Desa Wonosari, Kecamatan Wonosari 
Penduduk Desa Piyaman memiliki berbagai macam pekerjaan yang mana persentase paling besar adalah wiraswasta, yaitu sebesar $16 \%$. Menurut data pada tabel 1 persentase pengangguran Desa Piyaman cukup tinggi, yaitu $18,6 \%$.

Tabel 1. Data Kependudukan Berdasarkan Pekerjaan

\begin{tabular}{|c|c|c|c|c|c|c|}
\hline \multirow[b]{2}{*}{ No Kelompok } & \multicolumn{2}{|c|}{ Jumlah } & \multicolumn{2}{|c|}{ Laki-laki } & \multicolumn{2}{|c|}{ Perempuan } \\
\hline & $\mathrm{n}$ & $\%$ & $\mathrm{n}$ & $\%$ & $\mathrm{n}$ & $\%$ \\
\hline 1 BELUM/TIDAK BEKERJA & 1647 & $18.60 \%$ & 842 & $9.51 \%$ & 805 & $9.09 \%$ \\
\hline 2 PELAJAR/MAHASISWA & 1493 & $16.86 \%$ & 763 & $8.62 \%$ & 730 & $8.24 \%$ \\
\hline 3 WIRASWASTA & 1417 & $16.00 \%$ & 1002 & $11.32 \%$ & 415 & $4.69 \%$ \\
\hline 4 MENGURUS RUMAH TANGGA & 1190 & $13.44 \%$ & 0 & $0.00 \%$ & 1190 & $13.44 \%$ \\
\hline 5 PETANI/PERKEBUNAN & 784 & $8.85 \%$ & 252 & $2.85 \%$ & 532 & $6.01 \%$ \\
\hline 6 BURUH HARIAN LEPAS & 711 & $8.03 \%$ & 566 & $6.39 \%$ & 145 & $1.64 \%$ \\
\hline 7 KARYAWAN SWASTA & 673 & $7.60 \%$ & 388 & $4.38 \%$ & 285 & $3.22 \%$ \\
\hline 8 PEGAWAI NEGERI SIPIL (PNS) & 298 & $3.37 \%$ & 180 & $2.03 \%$ & 118 & $1.33 \%$ \\
\hline 9 PENSIUNAN & 162 & $1.83 \%$ & 111 & $1.25 \%$ & 51 & $0.58 \%$ \\
\hline 10 GURU & 86 & $0.97 \%$ & 21 & $0.24 \%$ & 65 & $0.73 \%$ \\
\hline
\end{tabular}

Pandemi Covid-19 di Indonesia menimbulkan penurunan perekonomian yang menyebabkan resesi di sepanjang tahun 2020. Angka kemiskinan di Indonesia juga meningkat sebanyak 1,13 juta penduduk sehingga total penduduk miskin di Indonesia sebanyak 27,55 juta penduduk. Peningkatan jumlah penduduk miskin ini banyak terjadi di daerah pedesaan. Selain itu, jumlah pengangguran di Indonesia juga meningkat. Ada sekitar 2,56 juta penduduk Indonesia yang menjadi pengangguran karena terjadinya pandemi Covid-19 [14]. Melihat data tersebut persentase pengangguran di Desa Piyaman diprediksi meningkat pada tahun 2021 dibanding tabel 1.

Berdasarkan analisis data sekunder, Desa Piyaman memiliki tiga potensi desa, yaitu penggunaan panel surya sebagai sumber energi listrik di rumah, cagar budaya Joglo Citakan, dan kampung bakmi Jawa. Mengingat wiraswasta di Desa Piyaman sebagian besar adalah penjual bakmi Jawa, maka potensi yang dipilih untuk program pengabdian masyarakat adalah bakmi Jawa.

Survey perusahaan marketing InMobi menunjukkan bahwa penduduk Indonesia melakukan lebih banyak belanja secara online saat pandemi Covid-19. Pertumbuhan $e$ commerce juga meningkat pesat selama pandemi Covid-19. Berbagai macam barang bahkan bahan makanan dapat dibeli secara online. Hal ini lah yang mendukung pertumbuhan $e$ commerce [15]. Mengingat pertumbuhan tersebut, pengembangan potensi bakmi Jawa Desa Piyaman diarahkan pada perubahan metode pemasaran yang semula secara langsung antara penjual dan pembeli menjadi secara tidak langsung melalui Tokopedia. Selain itu, penting untuk melakukan promosi melalui Instagram untuk menjangkau konsumen lebih luas.

Cara membuat bakmi frozen adalah:

1. Rebus bakmi sebentar agar tekstur lebih padat dan tidak mudah hancur saat dikemas

2. Setelah direbus, dinginkan bakmi dalam suhu ruangan sebelum dibekukan agar makanan dapat membeku dengan sempurna.
3. Pengemasan dilakukan dalam kemasan tertutup dan kedap udara (Vacuum) menggunakan plastik PE (Poly Ethyle) dan HDPE (High Density Polyethylene) agar bakteri atau benda asing tidak dapat masuk ke dalam makanan sehingga bakmi tidak dalam kondisi rusak.

4. Memberi label tanggal pembuatan dan tanggal kadaluarsa agar konsumen dapat mengetahui kelayakan makanan.

5. Bakmi dibekukan dengan disimpan dalam suhu dingin (18 derajat celcius).

Cara Menggunakan Fitur di Instagram Untuk Memaksimalkan Promosi:

\section{Instagram Feed/Story}

Fitur ini digunakan untuk membagikan foto atau video. Instagram Feed menjadi tampilan utama ketika pengguna lain membuka akun Instagram akun lain. Maka dari itu Instagram Feed harus dibuat semenarik mungkin agar pengguna lain tertarik untuk melihat foto atau video yang kita bagikan. Instagram Story dapat dilihat dengan memencet foto profil akun Instagram. Instagram Story hanya dapat dilihat selama 24 jam dan digunakan untuk meningkat interaksi dengan para pengikut.

\section{Instagram Ads}

Fitur yang dapat digunakan untuk mempromosikan atau mengiklankan produk secara berbayar untuk mencapai khalayak yang lebih luas dan sesuai dengan target pasar.

\section{Insight}

Fitur ini memberikan informasi penting mengenai jumlah pengunjung akun Instagram dan data diri pengunjung sehingga dapat membantu untuk memaksimal waktu membagikan foto atau video dan melihat lebih detail minat pengunjung.

\section{Like, Comment, dan Reply}

Fitur ini dapat digunakan pengunjung dan akun Instagram yang dikunjungi untuk saling berinteraksi.

\section{Caption dan Hashtag}

Caption digunakan untuk menceritakan pesan-pesan tertentu mengenai foto atau video yang dibagikan. Hashtag digunakan untuk menjangkau pengguna lain yang mungkin dapat tertarik dengan produk yang ditawarkan.

\section{Direct Message (DM)}

Fitur ini digunakan untuk mengirim dan menerima pesan dari pengguna lain sehingga memungkin terjadinya komunikasi yang lebih intens [16].

Cara Memasarkan Produk di Tokopedia:

1. Beri nama produk dengan menggunakan kata kunci yang sering cari pembeli di bagian pencarian.

2. Hindari menamai produk dengan kode-kode yang sulit dimengerti oleh pembeli. 


\section{Pemanfaatan Media Sosial dan E-Commerce Sebagai Upaya Pemasaran Bakmi Jawa di Desa Piyaman}

3. Gunakan sinonim dari nama produk atau nama-nama yang merujuk kepada produk sehingga dapat meningkatkan peluang terlihatnya produk oleh pembeli.

4. Gunakan rumus dasar penamaan produk [Jenis + Merk + Keterangan + Kata Promosi]

5. Membuat deskripsi produk yang jelas dan mudah dimengerti oleh pembeli secara cepat dengan memaksimalkan penjelasan manfaat dan keunikan dari produk [17]

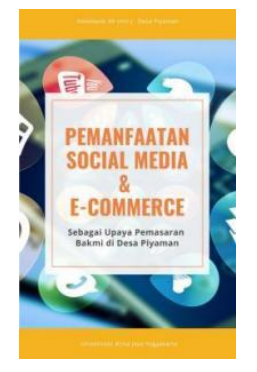

Gambar. 2 Cover E-Book Potensi Desa

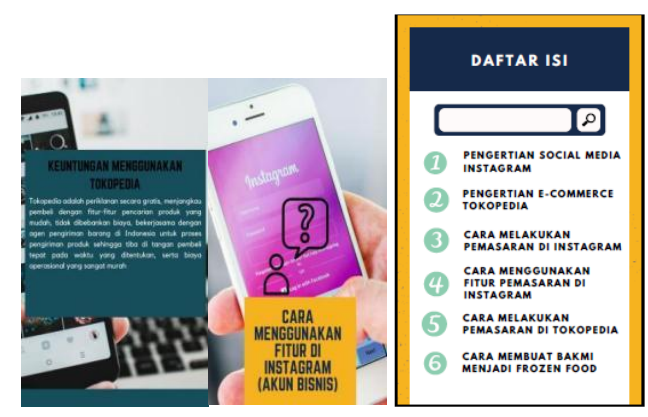

Gambar.3 Isi dari E-Book Potensi Desa

Kegiatan KKN ini menghasilkan luaran berupa e-book dan video yang akan memberikan informasi mengenai cara pengembangan potensi Desa Piyaman melalui promosi dan pemasaran digital dengan media sosial Instagram dan Tokopedia. Di dalam e-book dan video informasi yang diberikan adalah pengertian Instagram, pengertian Tokopedia, cara melakukan pemasaran di Instagram, cara menggunakan fitur pemasaran di Instagram, cara melakukan pemasaran di Tokopedia, dan cara pembuatan bakmi frozen.

\section{KESIMPULAN}

Program pengabdian masyarakat untuk Desa Piyaman yang diusulkan oleh penulis adalah pengembangan potensi desa bakmi Jawa dengan metode promosi dan pemasaran digital menggunakan Instagram dan Tokopedia. Selain itu, diperkenalkan juga cara pembuatan bakmi frozen untuk mempermudah pemasaran jarak jauh sebagai tindak lanjut pemasaran digital dengan konsumen yang lebih luas. Penyampaian program dilakukan melalui e-book dan video yang dapat diakses melalui internet. Dengan adanya program pengabdian ini diharapkan dapat membantu warga Desa Piyaman meningkatkan penjualan bakmi Jawa di masa pandemi Covid-19 dan membuka lapangan pekerjaan untuk menurunkan tingkat pengangguran di Desa Piyaman. Pelaksanaan metode promosi dan pemasaran digital serta diversifikasi bakmi frozen akan dapat berjalan baik dengan dukungan dari perangkat Desa Piyaman melalui pelatihan secara terencana.

\section{UCAPAN TERIMAKASIH}

Ucapan terimakasih diberikan kepada pihak LPPM Universitas Atma Jaya Yogyakarta yang telah memberikan kesempatan kepada penulis untuk membuat program pengabdian masyarakat dalam KKN pada masa pandemi Covid-19.

\section{DAFTAR PUSTAKA}

[1] K. Piyaman, "Piyaman," Website Piyaman. https://www.piyamanwonosari.desa.id/

[2] Made, "Bakmi Jawa Si Pemuas Rindu," Kompas.com, 2010. https://money.kompas.com/read/2010/03/22/14272272/bakmi.jawa.si. pemuas.rindu?page=all.

[3] "Sejarah Bakmi Jawa," Gudegnet. https://gudeg.net/direktori/1876/sejarah-bakmi-jawa.html (accessed Apr. 28, 2021).

[4] "Mi Mbah Wito (2): Desa Piyaman, Gudang Pedagang Bakmi Jawa," Kompas.com, 2009. https://travel.kompas.com/read/2009/10/15/11164115/ Travel Food Story (accessed Apr. 28, 2021).

[5] E. Katriana and Y. Sukmana, "3 Tantangan Utama yang Dihadapi UMKM Selama Pandemi Covid-19 Halaman all,” Kompas.com, 2020. https://money.kompas.com/read/2020/07/02/150000926/3-tantanganutama-yang-dihadapi-umkm-selama-pandemi-covid-19?page=all.

[6] D. Ryan and C. Jones, Understanding Digital Marketing: Marketing Strategies for Engaging the Digital Generation. London: Kogan Page, 2009.

[7] D. Chaffey and T. Hemphill, "Digital Business and E-commerce management," Pearson Education Limited. 2019.

[8] S. A. R. Putri, "MINORITISASI LGBT DI INDONESIA: CYBER BULLYING PADA AKUN INSTAGRAM @denarachman," Interak. J. Ilmu Komun., 2015, doi: 10.14710/interaksi,4,1,73-81.

[9] L. S. Bernadeta, "AKTUALISASI DIRI GENERASI Y DI INSTAGRAM," Interak. J. Ilmu Komun., 2017, doi: 10.14710/interaksi.6.1.93-109.

[10] "Tokopedia Jadi e-Commerce dengan Kunjungan Tertinggi di RI," CNN Indonesia, Jakarta, Feb. 25, 2021.

[11] Saryono, Metode Penelitian Kualitatif. Bandung: Alfabeta, 2010.

[12] M. B. Miles, A. M. Huberman, and J. Saldaña, Qualitative Data Analysis. SAGE, 2013.

[13] Sugiyono, Metode penelitian pendidikan: (pendekatan kuantitatif, kualitatif dan $R \&$ D). Bandung: Alfabeta, 2008.

[14] A. Librianty, "Setahun Corona Covid-19, Begini Kondisi Ekonomi Indonesia," Liputan6, Mar. 02, 2021.

[15] S. Makkl, "Netizen Indonesia Gencar Belanja Online Saat Pandemi," cnnindonesia.com, Feb. 23, 2021.

[16] R. K. Nistanto, "Cara Memakai 6 Fitur Instagram untuk Mendongkrak Bisnis Halaman all," Kompas.com, Nov. 09, 2018.

[17] ]Tokopedia, "Perhatikan Tips Ini Agar Jualan Ditaksir Pembeli!," Tokopedia, Jan. 19, 2021. https://seller.tokopedia.com/edu/caramenarik-pembeli-dengan-tampilan-toko/. 


\section{PENULIS}

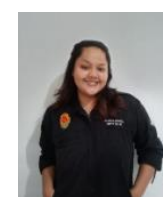

Agata Bening Arinta, prodi Teknik Sipil, Fakultas Teknik, Universitas Atma Jaya Yogyakarta.

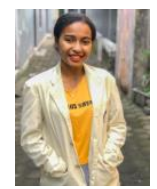

Inboki Insoraki Ayu Marjen, prodi Ekonomi Pembangunan, Fakultas Bisnis dan Ekonomi, Universitas Atma Jaya Yogyakarta.

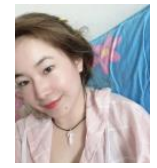

Cindy Angela Nayoan, prodi Akuntansi,, Fakultas Bisnis dan Ekonomi, Universitas Atma Jaya Yogyakarta.

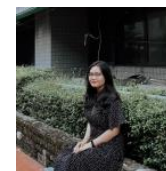

Tesya Lonika Samson, prodi Ilmu Hukum, Fakultas Hukum, Universitas Atma Jaya Yogyakarta.

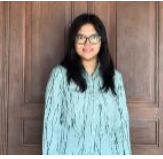

Fortuna Alya Azhari, prodi Informatika, Fakultas Teknologi Industri, Universitas Atma Jaya Yogyakarta.

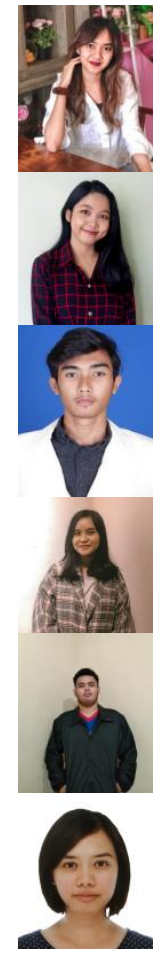

Yustina Violieta Prabawati, prodi Ilmu Komunikasi, Fakultas Ilmu Sosial dan Ilmu Politik, Universitas Atma Jaya Yogyakarta.

Evangelisca Trisna Herlin Adinda, prodi Sistem Informasi, Fakultas Teknologi Industri, Universitas Atma Jaya Yogyakarta.

I Gede Ari Chandra Wiguna, prodi Teknik Industri, Fakultas Teknologi Industri, Universitas Atma Jaya Yogyakarta.

Mercy Grace Olivia Manurung, prodi Ilmu Komunikasi, Fakultas Ilmu Sosial dan Ilmu Politik, Universitas Atma Jaya Yogyakarta.

Alvin Christa Yudiasmara, prodi Teknik Industri, Fakultas Teknologi Industri, Universitas Atma Jaya Yogyakarta.

Dr. apt. Sendy Junedi S.Farm., M.Sc., Dosen Program Studi Biologi, Fakultas Teknobiologi, Universitas Atma Jaya Yogyakarta 